\title{
Aula inaugural no Collège de France 5 de janeiro de 1960 (trecho)
}

\author{
CLAUDE LÉVI-STRAUSS
}

$[\ldots] \mathrm{P}$ ARA CONCLUIR esta aula, eu gostaria, senhor diretor, meus caros colegas, de evocar em poucas palavras a emoção muito excepcional que sente o antropólogo, quando entra numa casa cuja tradição, ininterrompida durante quatro séculos, remonta ao reinado de Francisco I. Sobretudo se ele é americanista, pois muitos laços o ligam a essa época, que foi quando a Europa recebeu a revelação do Novo Mundo e se abriu ao conhecimento etnográfico. Ele gostaria de ter vivido nela; que digo? ele vive nela todo dia em pensamento. E porque, muito singularmente, os índios do Brasil, onde fiz minhas primeiras armas, poderiam ter adotado como divisa: "eu manterei", verifica-se que o estudo deles possui uma dupla qualidade: a de uma viagem a uma terra distante e - mais misteriosa ainda - a de uma exploração do passado.

Mas, por essa razão também - e lembrando que a missão do Collège de France foi sempre ensinar a ciência que está se fazendo -, a tentação de uma queixa nos aflora. Por que essa cadeira foi criada tão tarde? Como é possível que a etnografia não tenha recebido seu lugar quando era ainda jovem e os fatos conservavam sua riqueza e seu frescor? Pois é em 1558 que gostaríamos de imaginar essa cadeira estabelecida, quando Jean de Léry, ao voltar do Brasil, redigia o seu primeiro livro e eram publicadas As singularidades da França antártica de André Thevet.

Certamente a Antropologia Social seria mais respeitável e mais sólida se o reconhecimento oficial lhe tivesse vindo no momento em que começava a delinear seus projetos. No entanto, a supor que tudo tivesse acontecido assim, ela não seria o que é hoje: uma pesquisa inquieta e fervorosa que atiça o pesquisador com interrogações tanto morais quanto científicas. Talvez fosse da natureza da nossa ciência aparecer simultaneamente como um esforço para recuperar um atraso e como uma meditação sobre uma defasagem, à qual devemos atribuir alguns de seus traços fundamentais.

Se a sociedade está na antropologia, a antropologia também está na sociedade: pois a antropologia pôde ampliar progressivamente o seu objeto de estudo até incluir a totalidade das sociedades humanas; contudo, ela surgiu num período tardio da história dessas sociedades e num pequeno setor da Terra ha- 


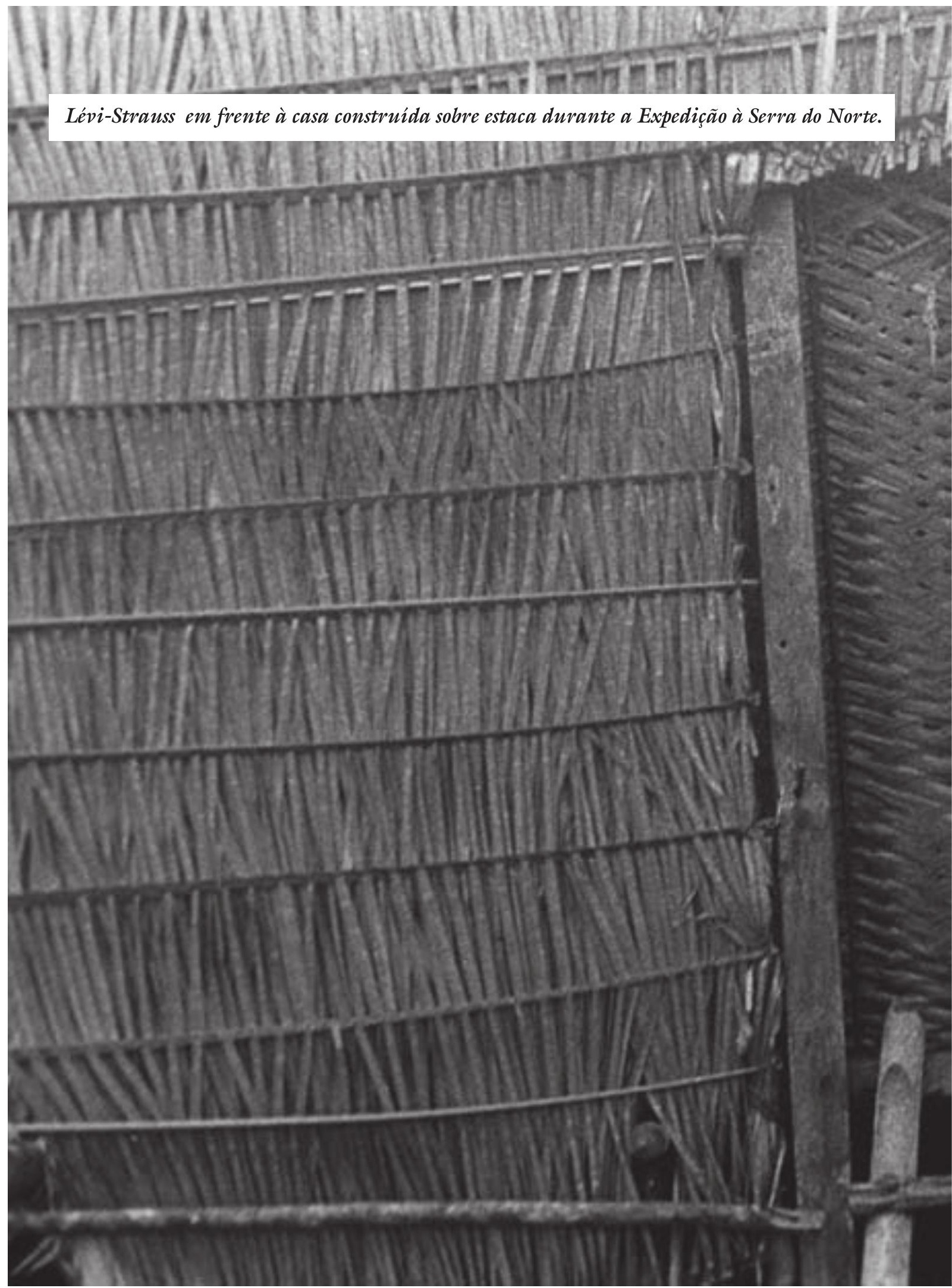




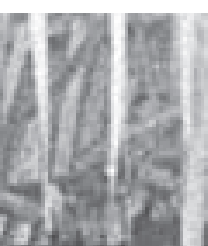

asidi?
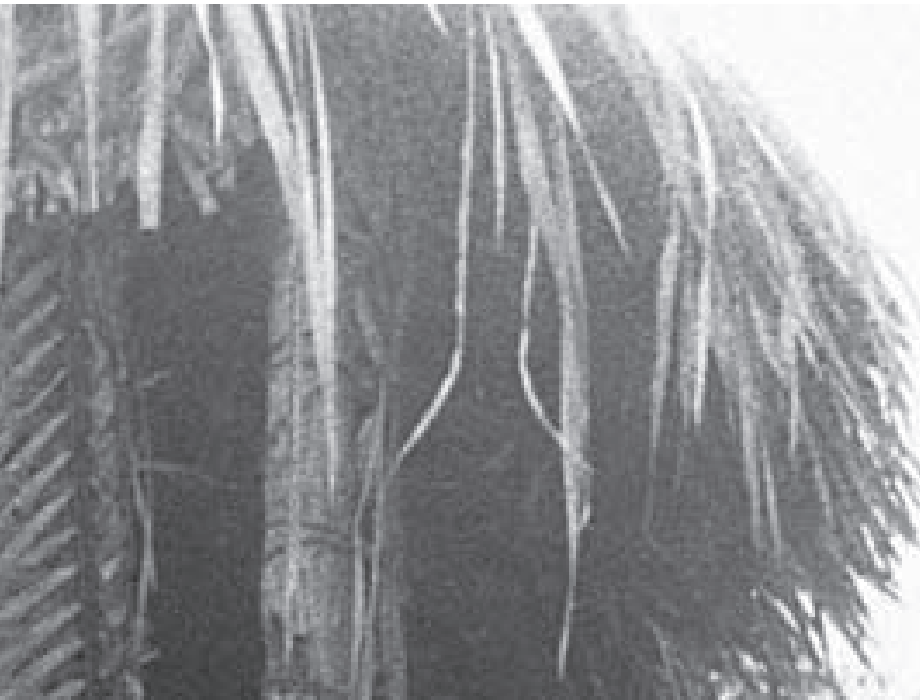

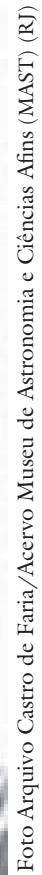

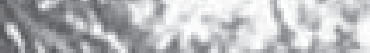

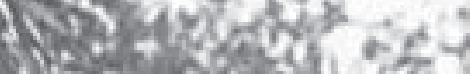

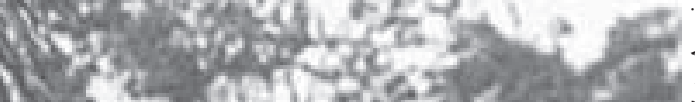

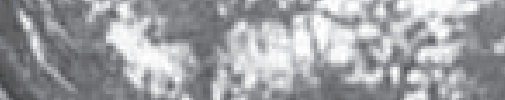

W.
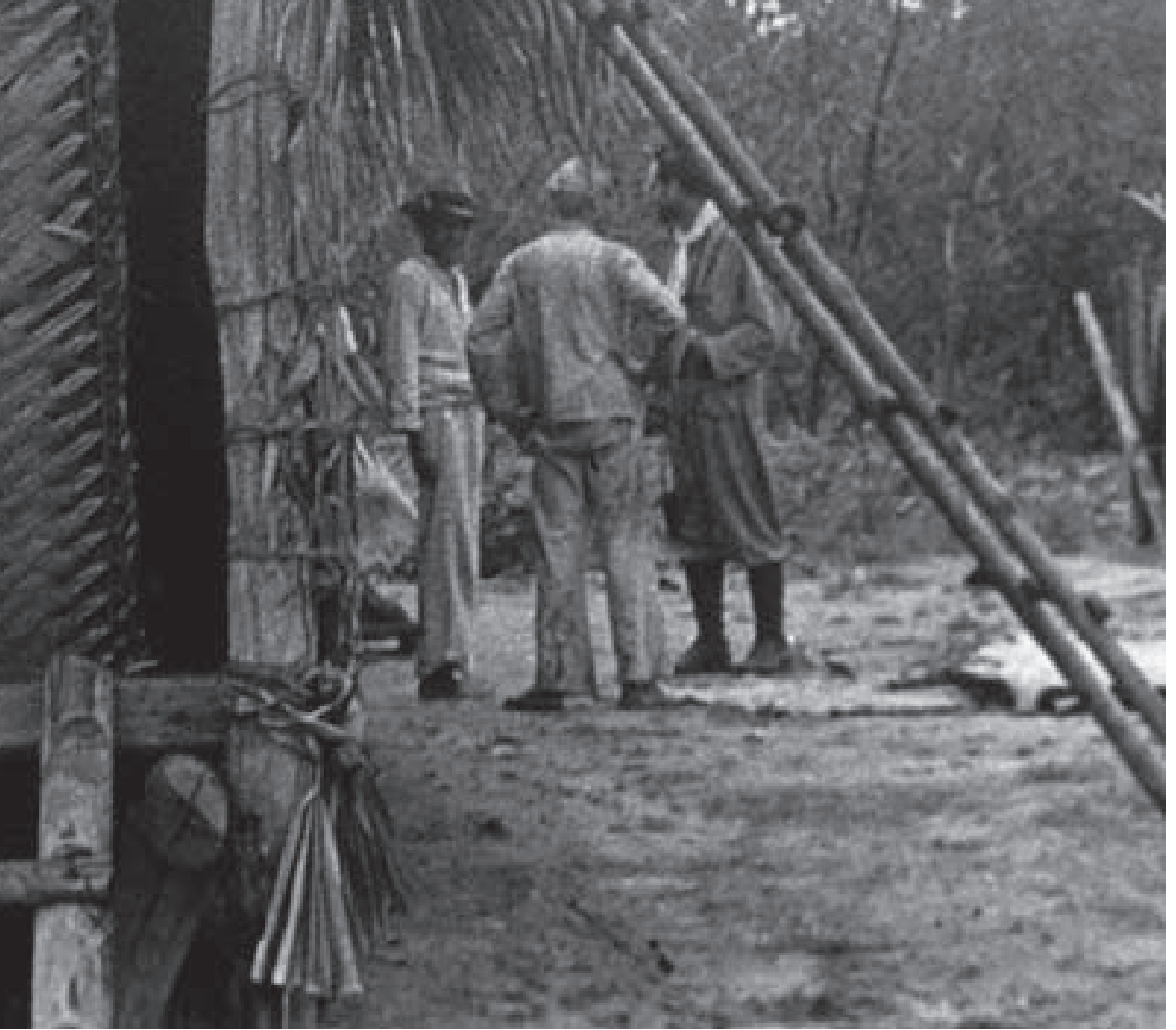


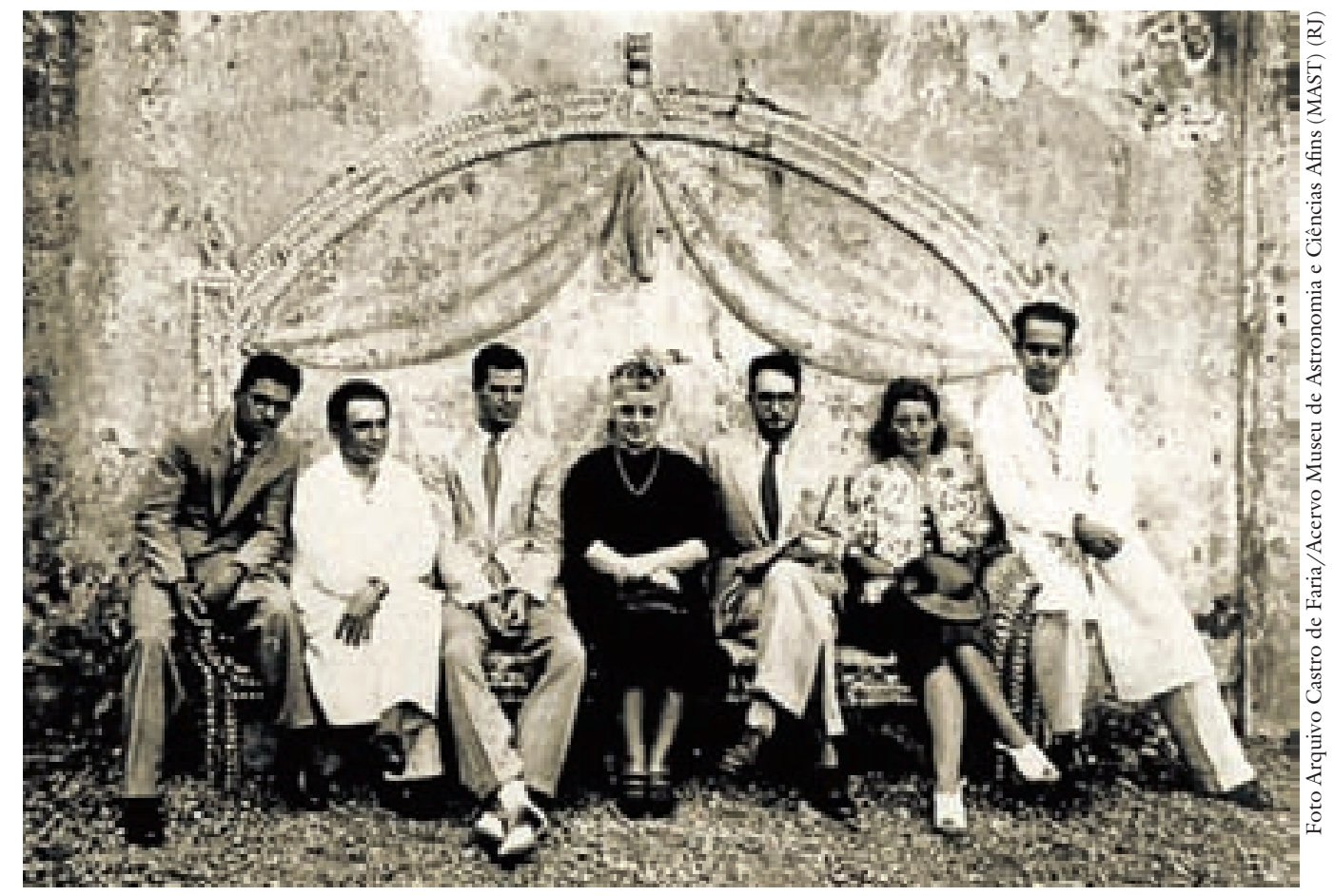

Da esq. para a dir.: Edson Carneiro, Raimundo Lopes, Charles Wagley, Heloisa Alberto Torres, Claude Lévi-Strauss, Ruth Landes e Luiz de Castro Faria. Rio de Janeiro, 1939.

bitada. Mais do que isso, as circunstâncias do seu aparecimento têm um sentido compreensível apenas quando situadas no quadro de um desenvolvimento social e econômico particular: percebe-se então que elas se acompanham de uma tomada de consciência - quase um remorso - de que a humanidade tenha podido permanecer por tanto tempo alienada de si mesma; e, sobretudo, de que essa fração da humanidade que produziu a antropologia tenha sido a mesma que fez, de tantos outros homens, um objeto de execração e de desprezo. Sequela do colonialismo, como é dito às vezes de nossas pesquisas. As duas coisas estão certamente ligadas, mas nada seria mais falso do que tomar a antropologia como o último avatar do espírito colonial, uma ideologia envergonhada que lhe ofereceria uma chance de sobrevivência.

O que chamamos Renascimento foi, para o colonialismo e para a antropologia, um nascimento verdadeiro. Entre um e a outra, enfrentados desde sua comum origem, um diálogo equívoco se manteve durante quatro séculos. Se o colonialismo não tivesse existido, o crescimento da antropologia teria sido menos tardio; mas é possível também que a própria antropologia não tivesse sido incitada, como se tornou seu papel, a colocar o homem inteiro em causa em cada um de seus exemplos particulares. Nossa ciência chegou à maturidade no dia em que o homem ocidental começou a compreender que nunca compreenderia a si mesmo enquanto na superfície da Terra uma única raça, ou um único povo, fosse tratado por ele como um objeto. Somente então a antropologia pôde se 
afirmar pelo que ela é: um empreendimento que renova e expia o Renascimento, para estender o humanismo à escala da humanidade.

Permitam então, meus caros colegas, após ter homenageado os mestres da Antropologia Social no começo desta aula, que minhas últimas palavras sejam para esses selvagens, cuja obscura tenacidade nos oferece ainda o meio de dar aos fatos humanos suas verdadeiras dimensões: homens e mulheres que, neste instante em que falo, a milhares de quilômetros daqui, em alguma savana roída por queimadas ou numa floresta inundada de chuva, retornam ao acampamento para compartilhar uma magra ração e evocar juntos os seus deuses; esses índios dos trópicos, e seus semelhantes de outras partes do mundo, que me ensinaram seu pobre saber no qual reside, porém, o essencial dos conhecimentos que os senhores me encarregaram de transmitir a outros; índios, infelizmente, condenados em breve à extinção, sob o choque das doenças e dos modos de vida - para eles mais horríveis ainda - que lhes trouxemos, e em relação aos quais contraí uma dívida da qual eu não estaria livre, mesmo se, neste lugar a que fui designado, pudesse justificar a ternura que me inspiram e o reconhecimento que lhes devo, continuando a me mostrar tal como fui entre eles e tal como, entre os senhores, eu gostaria de não deixar de ser: o aluno e a testemunha deles.

Publicado em Hors Série - La Lettre du Collège de France, Claude Lévi-Strauss - Centième anniversaire, Novembre 2008. Tradução de Paulo Neves. O original em francês - "Leçon inaugurale au Collège de France 5 Janvier 1960 (extrait)" - encontra-se à disposição do leitor no IEA-USP para eventual consulta.

Recebido em 16.7.2009 e aceito em 21.8.2009. 